1. Senior Registrar

Department of Neurosurgery

K.M.D.C and Abbasi Shaheed Hospital Karachi.

2. MD Resident

Department of Emergency

Medicine Ziauddin University

Hospital Karachi.

3. MD Resident

Department of Emergency

Medicine Ziauddin University

Hospital Karachi.

4. House Officer

DUHS and Civil Hospital, Karach

5. Research Fellow BMU

Correspondence Address:

Dr. Ahmed Ali C/O Dr. Syed Muneeb A-139 Block-i, North Nazimabad,

Karachi.

doctor.karachi@gmail.com

Article received on:

27/06/2015

Accepted for publication:

30/07/2015

Received after proof reading:

09/09/2015

\title{
POST HEMORRHOIDECTOMY PAIN RELIEF; OUTCOME OF LOCAL ANESTHESIA
}

\author{
Dr. Syed Muhammad Maroof Hashmi ${ }^{1}$, Dr. Shua Nasir ${ }^{2}$, Dr. Lal Shehbaz ${ }^{3}$, \\ Dr. Muhammad Absar Anwar ${ }^{4}$, Ahmed Ali ${ }^{5}$
}

\begin{abstract}
Background: The aim of my study is to evaluate post-operative pain relief on patients who had hemorrhoidectomy. Materials and Methods: 300 patients who had hemorrhoidectomy were divided equally in to three groups, according to anesthesia type, group 1 (local anesthesia and sedation), while spinal anesthesia was group 2 and general anesthesia was considered to be group 3. Pain relief, post-operative complications, hospital staying time were measured and compared between the three groups. Period: Study was performed between Jan 2012 to Dec 2014. Results: The study showed that patients who had local anesthesia infiltration and sedation a significant decrease of post-operative total pain scores at $6 / 12 / 18 / 24$ hours of more than $50 \%, 200 / 240 / 300 / 320$ out of 1000 points in group II as compared to $420 / 500 / 540 / 580,700 / 680 / 660 / 660$ in 3rd groups respectively. The total postoperative analgesia doses in the 3 groups were 120:140:180 respectively, total hospital staying time were 130:210:260 days, headache in the ratio of 0:8:1, urine retention in 0:6:1 patients, nausea and vomiting in 0:1:5 patients were reduced by $30 \%$,. P-value $<0.05$. On the other hand, spinal anesthesia which is group 2 showed slight decline of patients numbers who had respiratory symptoms, hypotension and urticarial.Conclusion: Post-operative pain, analgesia, total cost, hospital staying time, nausea and vomiting have been significantly reduced by local anesthesia infiltration compared to non-infiltrated groups while spinal anesthesia had a higher rate in post-operative urine retention, headache and hypotension compared to local anesthesia with sedation and general anesthesia. Respiratory symptoms, urticaria, were slightly reduced in local anesthesia with sedation compared to spinal and general anesthesia.
\end{abstract}

Key word: Pain, local anesthesia analgesia complications, cost, hospital stay, and Hemorrhoidectomy.

Article Citation: Hashmi SMM, Nasir S, Shehbaz L, Anwar MA, Ali A. Post hemorrhoidectomy pain relief; outcome of local anesthesia. Professional Med J 2015;22(9):11071110. DOI: $10.17957 / T P M J / 15.2998$

\section{INTRODUCTION}

Hemorrhoids are congested veins around the anorectal area and is estimated that more three quarters of people will have hemorrhoids in their lives. Hemorrhoids are most common among adults ages $4^{\text {th }}$ to $6^{\text {th }}$ decade. Hemorrhoids are also common in gestation. ${ }^{1,2}$ While one out of ten patients may require surgery. ${ }^{3}$

General or spinal anesthesia provides excellent surgical conditions for surgeons. On the other hand, patients may have more hospital stay, mobilize time and higher costs. Moreover, they were more liable to have urine retention, headache, nausea and vomiting. ${ }^{4}$

Local anesthesia has become a popular practice in many open surgical procedures to use of local anesthetics for postoperative pain relief. ${ }^{5}$ The purpose of this randomized prospective clinical study was to evaluate postoperative pain, analgesia, cost, hospital stay and complications such as: (headache, urine retention, hypotension, respiratory symptoms, urticaria, nausea and vomiting) in Hemorrhoid surgery by using local infiltration and sedation and to compare it with spinal and general anesthesia.

\section{MATERIALS AND METHODS}

Between January 2012 to December 2014, 300 patients who had hemorrhoidectomy were included in the study. All participants gave their informed consent for inclusion in the study. The patients who were given local anesthesia and 
sedation were informed about the procedure in details before they gave their informed consent. The trial was approved by the local ethics committee and was performed in line with the Declaration of Pakistan Ethical and Medical services.

The patients were divided in to three groups according to type of anesthesia usage; group I was those patients who had local anesthesia, that is 20 cc bupivacaine hydrochloride $0.5 \%$ with adrenaline and lignocaine hydrochloride $2 \%$ were injected around the anal skin, and intersphincter plane and sedation $2 \mathrm{cc}$ fentanyle and $2 c c$ dormecium were given intravenously. On the other hand, spinal anesthesia was used in group 2 and general anesthesia in group 3.

All Patients had mean age 45 years and range (15- 75 years), they have grade 3 or 4 hemorrhoid and there were no history of bupivacaine allergy. Post-operative anal pain severity was evaluated by score in a range (0-10) and recorded at 6,12 , 18 and 24hours post-operative time in all patients who were included in the study.

All patients received analgesics according to a standard postoperative protocol with Diclofenac Sodium $1 \mathrm{mg} / \mathrm{kg}$ intramuscular injection or Pethidine $1 \mathrm{mg} / \mathrm{kg}$ intramuscular injection was administered on request in the ward.

The dose and time of administration of Diclofenac Sodium and Pethidine were recorded within the first 24 hours post-operatively. Hospital staying time, urine retention, headache, hypotension, respiratory symptoms, urticaria, nausea and vomiting were evaluated in the study.

Data transferred to Statistical Package of Social Science (SPSS version 16); Comparing means and cross-tabulation between three groups for subjected variables in this study to evaluate the benefits of the use of local infiltration during such a surgical procedure, considering ( $\mathrm{P}$-value < 0.05) statistically significant.

\section{RESULTS}

Although, 307 patients were included in the study, seven patients were excluded due to no compliance of the procedure and conversion to general anesthesia was done.

The Age of patients were ranged between (1575 years) with mean 45years, while the patients gender was 204 males and 96 females $(\mathrm{m} / \mathrm{f}$ ratio 68:32) all were distributed equally in the three groups according to anesthesia type that used. (Table-I) and all patients were included in the study had Piles grade 3, 4, (202 were grade three 98 grade 4) furthermore, there were 58:56:57 smoker and 1:1:1 alcoholic in the three groups respectively.

\begin{tabular}{|c|c|c|c|}
\hline & Group 1 & Group 2 & Group 3 \\
\hline Age range & $15-75$ & $15-75$ & $15-75$ \\
\hline Gender M:F & $70: 30$ & $72: 28$ & $62: 38$ \\
\hline Table-I. Type of anesthesia and age and gender
\end{tabular}

Total post-operative anal pain score was recorded at $(6,12,18,24)$ hours. So, it was reducedby50 \% that is $200 / 240 / 300 / 320$ in group 1 compared to $420 / 500 / 540 / 580$ in group 2 and $(700 / 680 / 660 / 660)$ in group 3 , respectively. (P-value < 0.001) (Table-II).

Our study showed that there were no significant differences regarding post-operative pain among smoker versus nonsmoker and alcoholic versus non- alcoholic patients. Drugs consumption (Pethedine or Diclofenac sodium injections) in the postoperative period was significantly reduced by one third of the total injections; they were 120 in group 1 compared to 140 group 2, and 180 in group3, respectively. (P-value $<0.001)$.(Table-II)

\begin{tabular}{|c|c|c|c|c|}
\hline & Group 1 & Group 2 & Group 3 & P value \\
\hline Total analgesia doses & 120 & 140 & 180 & $<.001$ \\
\hline Total pain scores6/12/18/24 hours & $200 / 240 / 300 / 320$ & $420 / 500 / 540 / 580$ & $700 / 680 / 660 / 660$ & $<0.001$ \\
\hline Total Hospital stay & 130 & 210 & 260 & $<0.001$ \\
\hline \multicolumn{2}{|c|}{ Table-Il. Type of anesthesia and analgesia injections, total pain scores, and hospital stay } \\
\hline
\end{tabular}


The total hospital staying time was reduced by more than $30 \%$ it was 210 and 260 days in group 2and 3 compared to 130 days in group 1 respectively. (P-value was $<0.001)$. (Table-II)

Those patients who had urine retention, headache and hypotension were much higher in group 2(6:8:3)compared to group 1 and 3 (0:0:1) and $(1: 1: 1)$ respectively. On the other hand, there were more respiratory symptoms, urticaria, nausea and vomiting in group 3(4:2:5) compared to $(0: 1: 0)$ and(1:1:1) in group 1 and 2 respectively. (Table-III). While there were no patient who had bradycardia nor wound infection in the study.

\begin{tabular}{|c|c|c|c|c|}
\hline & Group 1 & Group 2 & Group 3 & P value \\
\hline $\begin{array}{c}\text { Urine retention } \\
\begin{array}{c}\text { Respiratory } \\
\text { discomfort }\end{array}\end{array}$ & 0 & 6 & 1 & 0.011 \\
\hline Headache & 0 & 1 & 4 & 0.071 \\
\hline Hypotension & 1 & 3 & 1 & 0.001 \\
\hline Urticaria, & 1 & 1 & 2 & 0.443 \\
\hline $\begin{array}{c}\text { Nausea and } \\
\text { vomiting }\end{array}$ & 0 & 1 & 5 & 0.028 \\
\hline Table-III. Type of anesthesia and surgery \\
\hline \multicolumn{4}{c}{ complications } \\
\hline
\end{tabular}

So the P-value was significantly reduced in group 1 compared to group 2 and 3 for urine retention(0.11), headache (0.001) , nausea and vomiting(0.028), while it was not the case for respiratory symptoms, urticarial and hypotension who had $p$-value $(0.071),(0.776)$ and $(0.443)$ as per groups respectively.

\section{DISCUSSION}

Hemorrhoidectomy can be performed safely as day-case under general anesthesia; however, complications may result from general anesthesia especially in advanced age while caudal or spinal anesthesia has been used as an alternative to general anesthesia for hemorrhoid surgery, but all of them require a trained anesthetist and have numerous complications. ${ }^{6}$

Furthermore, spinal headaches may occur in up to 40 percent of those who undergo a spinal tap. ${ }^{7}$ lt is found that the rate is more in young age patients, female, needle size ${ }^{8}$ and this may lead to restrict daily activities and more hospital stay.

Lignocaine provides potent initial pain relief, and adrenaline reduces bleeding in the operative field due to vasoconstriction. Lignocaine with adrenaline provides enough time for not only hemorrhoidectomy but also transportation to home. $^{9}$

This study is correlated with other studies by combination of local anesthesia perianal blockade and sedation, in anorectal surgery which allows less requirement of intravenousfluidadministration that result in less incidence of urinary retention (10). On the other hand spinal or caudal anesthesia and pudendal (ischiorectal nerve blocks) may result in urinary retention with the reported incidence of postoperative urinary retention varies widely, from $<1 \%$ to $>50 \% .{ }^{11}$ Spinal anesthesia may cause hypotension and correction of the condition by excessive intravenous fluid infusion may lead tooverextension of urinary bladder. This inhibits detrusor function, and normal reflex is not restored even after emptying urinary bladder with a catheter. ${ }^{12}$

Early ambulation and doctor patients' interaction during the procedure were noticed in group 1 of this study as they were mentioned in other studies. ${ }^{13}$

\section{CONCLUSION}

Hemorrhoidectomy by Local anesthesia and Sedation is an alternative mode of anesthesia that surgeons can safely carry out by their own. It was associated with a shorter hospital stay, lower pain scores and less post-operative analgesic doses.

It has lower post-operative complications (respiratory symptoms, nausea and vomiting) than general anesthesia which supports the routine use of local anesthesia for hemorrhoidectomy. Local perianal nerve block for hemorrhoidectomy is feasible and safe, cost effective, and superior to spinal block due to a lower incidence of post-operative urinary retention, headache and hypotension.

Copyright@ 30 July, 2015. 


\section{REFERENCES}

1. Baker H. Hemorrhoids. In: Longe JL, ed. Gale Encyclopedia of Medicine. 3rd ed. Detroit: Gale; 2006: 1766-1769.

2. Chong PS, Bartolo DCC. Hemorrhoids and fissure in ano. Gastroenterology Clinics of North America. 2008;37:627-644

3. Hemorrhoids: Expanded Version" published 2011. American Society of Colon \& Rectal Surgeons. Accessed 9 December 2013.

4. Nourian Najafabadi M, Jebel Ameli M. Comparative Study of Relative Frequency of Nausea and Vomit, Satisfaction of Patient and Surgeon in Various Methods of Anesthesia in Patients under Cataract Surgical Operation. Journal of Mazandaran University of Medical Sciences and Health Service. 16th issue, No.55, Dec. 2006, Jan. 2007; p. 18-26.

5. Luck AJ, Hewett PJ. Ischiorectal fossa block decreases post hemorrhoidectomy pain: randomized, prospective, double-blind clinical trial. Dis Colon Rectum 2000; 43:142-5.

6. Kushwaha R, Hutchings W, Davies C, Rao NG. Randomized clinical trial comparing day-care open hemorrhoidectomy under local versus general anesthesia. Br J Surg. 2008; 95(5):555-563.

7. Post-dural (post-lumbar) puncture headache.
International Headache Society. http://ihs-classification.org/en/02_klassifikation/03_teil2/07.02.01_nonvas cular.html. Accessed Jan. 22, $20 \overline{15}$.

8. Wadud R1, Laiq N, Qureshi FA, Jan AS. The frequency of postdural puncture headache in different age groups. J Coll Physicians Surg Pak. 2006 Jun;16(6):38992.

9. Potchavit A. Perianal block for ambulatory hemorrhoidectomy, an easy technique for general surgeon. J Med Assoc Thai. 2009; 92(2):195-197.

10. Lohsiriwat L, Lohsiriwat D. Ambulatory anorectal surgery under perianal anesthetics infiltration: analysis of 222 cases. J Med Assoc Thai. 2007;90(2): 278-281.

11. Sarain SM Walton MJ, Singh HP Clark DI. Can a urinary tract symptom score predict the development of postoperative urinary retention in patients undergoing lower limb arthroplasty under spinal anaesthesia? A prospective study. Ann R Coll Surg Engl 2006;88:394-8.

12. Diouf $E$ Tubach $F$ et al. Predictive factors of early postoperative urinary retention in the postanesthesia care unit. Anesth Analg 2005;101:592-6.

13. Mutihir JT, Aisien AO, Ujah IA. Anaesthetic experience in female sterilization at Jos University Teaching Hospital, Nigeria. East African Medical Journal. 2007; 84:374-378.

\begin{tabular}{|c|l|l|}
\hline \multicolumn{3}{|c|}{ AUTHORSHIP AND CONTRIBUTION DECLARATION } \\
\hline Sr. \# & \multicolumn{1}{|c|}{ Author-s Full Name } & \multicolumn{1}{c|}{ Contribution to the paper } \\
\hline 1 & Syed M. Maroof Hashmi & Concept Writing Drafting \\
2 & Dr Shua Nasir & Writing Drafting \\
3 & Dr Lal Shehbaz & $\begin{array}{l}\text { Data Collection ,Statistical } \\
\text { work } \\
\text { Data Collecting, compiling }\end{array}$ \\
4 & Dr M. Absar Anwar & Final Layout. Data entering \\
5 & Ahmed Ali & \\
\hline
\end{tabular}

